\title{
Ectopic tooth: an unusual cause of headache
}

\author{
Dustin Anderson MD PhD, S. Nizam Ahmed MD
}

— Cite as: CMAJ 2017 May 29;189:E749. doi: 10.1503/cmaj.161366

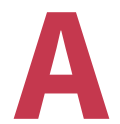

27-year-old woman was referred to neurology from her family physician's office for evaluation of her seizures. The patient also had chronic headaches that were refractory to standard medical treatment. She described these as unilateral (right-sided), throbbing, of moderate to severe intensity, and accompanied by nausea and photophobia. A neurological examination was unremarkable. Migraine without aura was considered the most likely diagnosis; however, because the headaches were treatment resistant, we ordered computed tomography of the head and sinuses. The imaging showed a hyperdensity obstructing the right maxillary sinus (Figure 1 ), most in keeping with an ectopic tooth. We diagnosed sinusitis and consulted otolaryngology for potential surgical intervention. The tooth was extracted under general anesthesia, without complication. The patient's headaches have now entirely abated.

The incidence of supernumerary teeth in the general population is $0.1 \%-1 \% .{ }^{1}$ An ectopic tooth in the maxillary sinus is particularly uncommon, having been reported only in case reports and small case series. ${ }^{1-3}$ Ectopic maxillary teeth may present with numerous signs and symptoms, all of which lack specificity; sensitivity to hot and cold, numbness and swelling of the cheek, epiphora, oroantral fistula, sinusitis and headache have all been described in the literature. ${ }^{1-3}$ Here we have described an uncommon case of an ectopic maxillary tooth presenting with features of migraine without aura. Sinusitis can mimic migraine ${ }^{4}$ and, in this case, was the most likely cause of headache. In clinical scenarios in which migraine does not improve with standard treatment, it is important to consider alternate diagnoses. Surgery remains the treatment modality of choice for symptomatic ectopic maxillary teeth. ${ }^{3}$

\section{References}

1. Dhingra S, Gulati A. Teeth in rare locations with rare complications: an overview. Indian J Otolaryngol Head Neck Surg 2015;67:438-43.

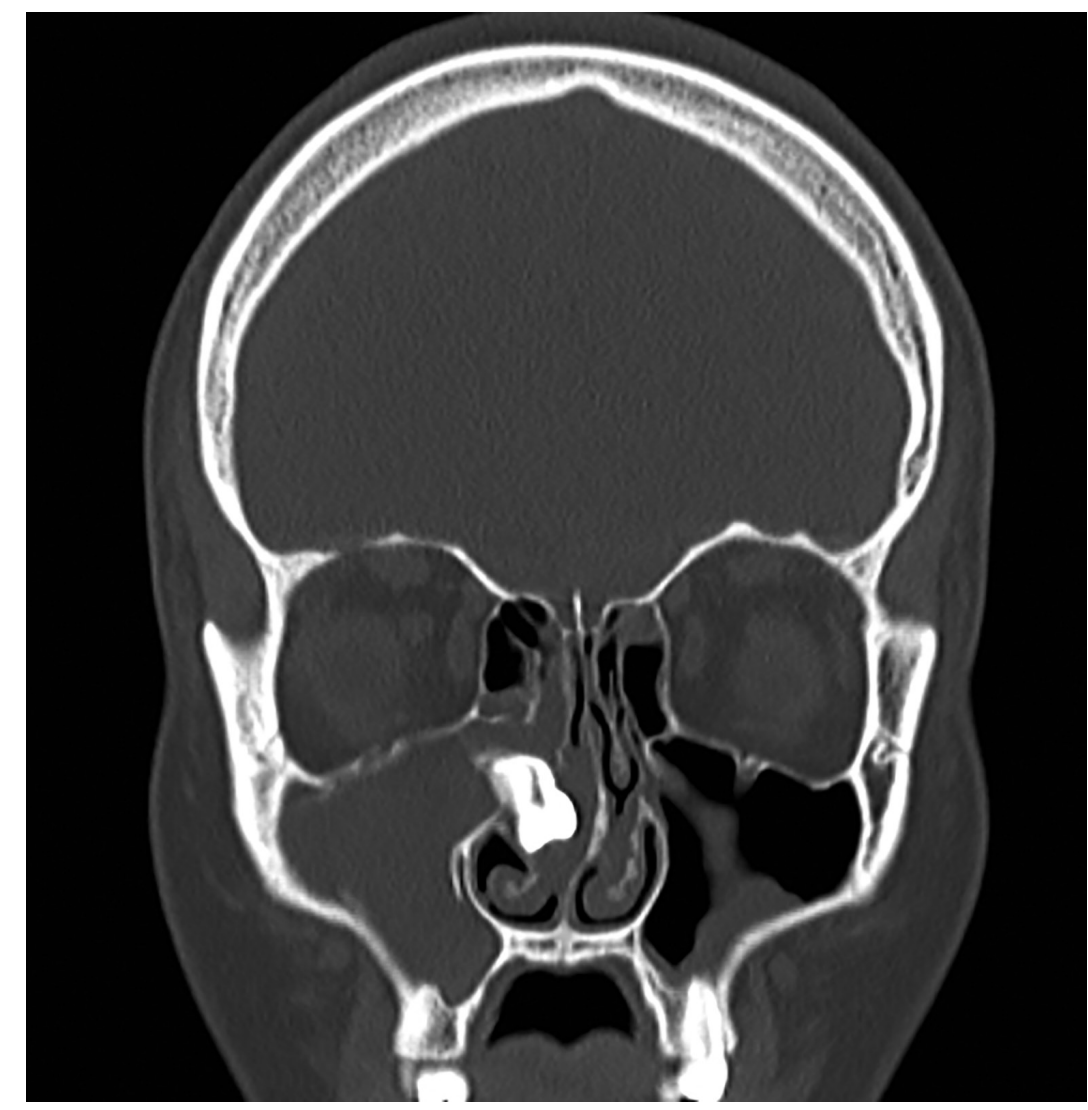

Figure 1: Coronal computed tomographic image showing an ectopic tooth in the right maxillary sinus of a 27 -year-old woman, with invasion into the naval cavity.

2. Nisa L, Giger R. Images in clinical medicine. Ectopic tooth in the maxillary sinus. N Engl J Med 2011;365:1232.

3. Ramanojam S, Halli R, Hebbale M, et al. Ectopic tooth in maxillary sinus: case series. Ann Maxillofac Surg 2013;3:89-92.

4. Marmura MJ, Silberstein SD. Headaches caused by nasal and paranasal sinus disease. Neurol Clin 2014;32:507-23.

Competing interests: None declared.

This article has been peer reviewed.

The authors have obtained patient consent.

Affiliation: Department of Medicine (Neurology), University of Alberta, Edmonton, Alta.

Correspondence to: S. Nizam Ahmed, snahmed@ualberta.ca 